\title{
Rancangan Kendali Otomatis Kipas Angin Berdasarkan Suhu Ruangan Dan Gerak Manusia
}

\section{Design Of Automatic Control Of Wind Flask Based On Space Temperature And Human Motion}

\author{
Simon Petrus ${ }^{1}$, Dadan Ramdan ${ }^{2}$, Marlan Swandana ${ }^{3}$ \\ Program Studi Teknik Elektro, Fakultas Teknik, Universitas Medan Area, Indonesia \\ Diterima: April 2019; Disetujui: April 2019; Dipublikasi: April 2019 \\ *Coresponding Email: simonps1@ gmail.com
}

\begin{abstract}
Abstrak
Pembuatan Kipas Angin Otomatis yang dikendalikan oleh suhu ruangan dan gerak manusia, dilatarbelakangi oleh perkembangan alat teknologi yang sangat pesat di jaman modern ini. Khususnya alat elektronik yang banyak digunakan untuk membantu meringankan pekerjaan manusia, sehingga besar akan kebutuhan listrik. Sedangkan sumber atau pembangkit arus listrik sangat terbatas. Penghematan merupakan salah satu solusi mengatasi besarnya pemakaian arus listrik. Untuk dapat mengoptimalkan penghematan listrik, maka dapat dilakukan dengan beralih pada alat elektronik yang bersifat otomatis atau membuat rancangan elektronik lainnya seperti halnya Kipas Angin Otomatis. Kipas Angin Otomatis menggunakan mikrokontroler Atmega8 yang mengendalikan sistem kipas angin berdasarkan suhu ruangan dan gerak manusia. Sensor yang digunakan adalah passive infrared receiver yang mendeteksi perubahan infra merah pasif.
\end{abstract}

Kata Kunci : Kipas Angin Otomatis, Mikrokontroler Atmega8, passive infra red

\begin{abstract}
The manufacture of an automatic fan is controlled by the temperature of the room and the motion of the human, backed by the development of technological tools that are very rapid in this modern era. Especially electronic devices are widely used to help alleviate human work, resulting in great demand for electricity. While the source or power plants is very limited. Saving is one solution toovercome the amount of electricity usage. To be able to optimize the power savings, it can be done by switching on electronic devices that are automatic or make other electronic designs such as an automatic fan. The automatic fan uses an atmega8 microcontroller that controls the fan system based on motion. The sensors used are passive infrared receiver which detects passive infrared changes.
\end{abstract}

Keywords : Automatic fan, Atmega8 Microcontroller, passive infra red

How to Cite: Petrus, S, Ramdan, D, Swandana, M \& Petrus. (2019), Rancangan Kendali Otomatis Kipas Angin Berdasarkan Suhu Ruangan Dan Gerak Manusia(Design Of Automatic Control Of Wind Flask Based On Space Temperature And Human Motion), JESCE (Journal or Electrical and System Control Engineering),2(2):43-53 


\section{PENDAHULUAN}

Perkembangan teknologi saat ini mendorong manusia untuk terus berpikir kreatif, tidak hanya menggali penemuan-penemuan baru, tapi juga memaksimalkan kinerja teknologi yang ada yang bermanfaat dalam meringankan kerja manusia dalam kehidupan sehari-hari. Sehingga semakin berkembang teknologi, maka besar kebutuhan akan listrik. Sedangkan sumber atau pembangkit listrik sangat terbatas. Rancangan kipas angin otomatis berdasarkan deteksi suhu dan gerak Manusia pada ruangan ini adalah merupakan sistem yang dapat membantu dalam kebutuhan sehari-hari dan sesuai kebutuhan yang diharapkan banyak orang dikalangan masyarakat yang menggunakan Kipas Angin, dengan tujuan untuk mendapatkan kenyamanan bagi masyarakat kalangan menengah kebawah maupun keatas.

Adapun yang menjadi rumusan masalah dalam penelitian ini adalah :

a) Bagaimana merancang suatu sistem pengaturan suhu ruangan/kamar secara otomatis berdasarkan gerak manusia dan suhu ruangan.

b) Bagaimana merangkai sistem dengan Mikrokontroler Atmega8 dan sensor suhu 2 buah agar sistem dapat bekerja sesuai dengan fungsinya.

c) Bagaimana membuat perangkat lunak atau program untuk menjalankan rangkaian mikrokontroler.

\section{Batasan Masalah}

Batasan masalah bertujuan untuk membatasi pembahasan dan agar masalah-masalah menjadi lebih terarah. Adapun batasan-batasan tersebut diantaranya :

a) Rancangan menggunakan kontroler Atmega8 sebagai pengendali sistem.

b) Rancangan menggunakan sensor suhu LM 35 untuk deteksi suhu ruang dan sensor pir untuk mendeteksi gerak manusia.

c) Rancangan menggunakan pemograman bahasa $\mathrm{C}$ dengan editor CV AVR versi 2.0.4.9 untuk menyusun program yang menjalankan sistem.

\section{Kegunaan Alat}

Diharapkan Kipas Angin Otomatis yang menggunakan mikrokontroler Atmega8 sebagai pengendali sistem kipas angin berdasarkan suhu ruangan dan gerak manusia, dan passive infrared receiver sebagai sensor mendeteksi 
perubahan infra merah pasif dapat bermanfaat diantaranya :

a) Mewujudkan sistem kendali yang dapat membantu penghematan energi listrik dengan mendeteksi suhu ruangan dan gerak manusia.

b) Membantu mengoptimalkan fungsi dari Kipas Angin bagi kalangan masyarakat pengguna Kipas Angin.

c) Membantu minat belajar mahasiswa lain untuk antusias dalam mempelajari dan mengembangkan mikrokontroller.

\section{Mikrokontroler AVR Atmega8}

Mikrokontroler

merupakan

komputer yang didalamnya terdapat berbagai macam fungsi yang digunakan untuk mengontrol peralatan elektronika, dengan menekankan efisiensi dan efektifitas biaya yang bisa disebut "pengendali kecil" dimana sebuah sistem elektronika yang sebelumnya banyak memerlukan komponen-komponen pendukung seperti IC (Integrated Circuit),TTL (Transistor Transistor Logic), dan CMOS (Circuit Metal Oxide Semiconductor) dapat direduksi/diperkecil dan akhirnya terpusat serta dikendalikan oleh Mikrokontroler.

AVR

Atmega8

adalah

Mikrokontroler CMOS 8-bit berarsitektur AVR RISC yang memiliki 8k byte inSystem Programmable Flash. Mikrokontroler dengan konsumsi daya rendah ini mampu mengeksekusi instruksi dengan kecepatan maksimum 16MIPS pada frekuensi 16MHZ.

\section{Konfigurasi Pin Atmega8}

Atmega8 memiliki 28 pin, yang masing-masing pin nya memiliki fungsi yang berbeda-beda baik sebagai port maupun fungsi yang lainnya.

Berikut ini adalah Gambar 2.1 Konfigurasi pin Atmega8

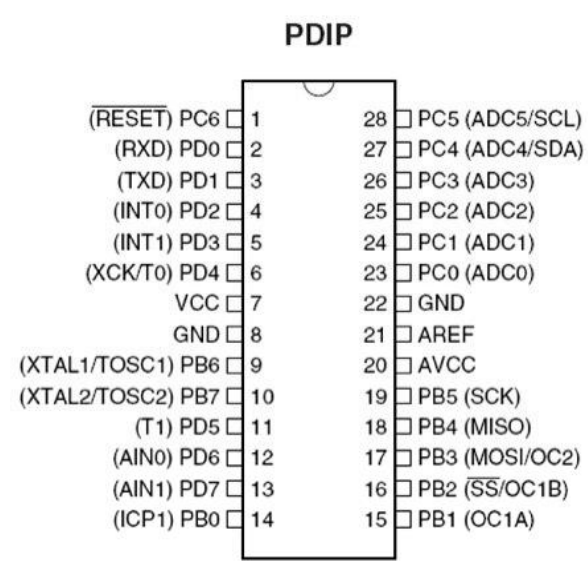

Sumber : http://www.circuitstoday.com

Gambar 1. Konfigurasi pin Atmega8

\section{Transistor}

Transistor yaitu komponen elektronik yang terbuat dari bahan semikonduktor yang mempunyai tiga kaki atau tiga elektroda (triode), kaki tersebut yaitu basis (B), kolektor (C) dan 
Emitor (E). Transistor berasal dari dua kata yaitu kata transfer dan resistor yang mengkhiaskan arti pemindahan atau peralihan bahan (semi konduktor) setengah penghantar menjadi penghantar pada suhu tertentu.

Secara umum transistor terbagi dalam 2 jenis :

a. Transistor Bipolar.

b. Transistor Unipolar.

Transistor bipolar bekerja dengan dua macam carrier, sedangkan unipolar satu macam saja, hole atau electron.

Tabel 1 Perbandingan Transistor Bipolar dan Unipolar.

\begin{tabular}{|l|c|c|}
\hline & BIPOLAR & UNIPOLAR \\
\hline Dimensi & Besar & Kecil \\
Daya & Besar & Kecil \\
Bandwidth & Lebar & Sempit \\
Respon & Tinggi & Sedang \\
Jenis Input & Arus & Tegangan \\
Impendans & Sedang & Tinggi \\
Input & & \\
\hline
\end{tabular}

Sumber : https://www.google.co.id

\section{Relay}

Relay adalah suatu peranti yang bekerja berdasarkan sifat elektromagnetik untuk menggerakan sejumlah kontaktor yang tersusun atau sebuah saklar elektronis yang dapat dikendalikan dari rangkaian elektronik lainnya dengan memanfaatkan tenaga listrik sebagai sumber energinya.

\section{Sensor Gerak atau PIR (Passive Infrared} Receiver).

PIR (Passive Infrared Receiver) merupakan sebuah sensor berbasiskan infrared. Sensor ini hanya merespon energi dari pancaran sinar inframerah pasif yang dimiliki oleh setiap benda yang terdeteksi olehnya. Benda yang bisa dideteksi oleh sensor ini biasanya adalah tubuh manusia.

\section{Sensor Suhu LM35}

Sensor suhu LM35 adalah komponen elektronika yang memiliki fungsi untuk mengubah besaran suhu menjadi besaran listrik dalam bentuk tegangan.

Berikut ini adalah karakteristik dari sensor LM35 :

a. Memiliki sensitivitas suhu, dengan faktor skala linier antara tegangan dan suhu $10 \mathrm{mVolt} /{ }^{\circ} \mathrm{C}$.

b. Memiliki ketepatan atau akurasi kalibrasi yaitu $0,5^{\circ} \mathrm{C}$ pada suhu $25^{\circ} \mathrm{C}$

c. Memiliki jangkauan maksimal operasi suhu antara $-55^{\circ} \mathrm{C}$ sampai $+150 \stackrel{\circ}{-} \mathrm{C}$.

d. Bekerja pada tegangan 4 sampai 30 volt. 
e. Memiliki arus rendah yaitu kurang dari $60 \mu \mathrm{A}$.

f. Memiliki pemanasan sendiri yang rendah (low-heating) yaitu kurang dari $0,1^{\circ} \mathrm{C}$ pada udara diam.

g. Memiliki impedansi keluaran yang rendah yaitu $0,1 \mathrm{~W}$ untuk beban 1 mA.

h. Memiliki ketidaklinieran hanya sekitar $\pm 1 / 4 \stackrel{\circ}{ } \mathrm{C}$.

\section{Dioda}

Dioda adalah dua lapisan elektroda $\mathbb{N}$ lok menggambarkan secara umum cara (katoda) dan lapisan P (anoda). Dimana Nerja rangkaian secara keseluruhan. berarti negatif, dan $\mathrm{P}$ adalah positif

\section{Power Supply (Catu Daya)}

Power supply atau sumber tegangan /catu daya adalah suatu alat atau sistem yang dapat menghasilkan arus listrik.

\section{Kipas Angin}

Kipas Angin, fungsi umumnya adalah sebagai pendingin udara, penyegar udara, ventilasi (exhaust fan) dan pengering umumnya yang memakai komponen tertentu.

\section{Motor AC}

\begin{tabular}{ccr} 
Motor & arus & \multicolumn{2}{r}{ bolak-balik } \\
menggunakan & arus & listrik yang
\end{tabular}

membalikkan arahnya secara teratur pada rentang waktu tertentu. Motor listrik memiliki dua buah bagian dasar listrik: "stator" dan "rotor". Stator merupakan komponen listrik statis dan Rotor merupakan komponen listrik berputar untuk memutar as motor.

\section{METODE PENELITIAN}

Untuk mempermudah perancangan alat digunakan Diagram blok sebagai langkah awal pembuatan alat. Diagram 
Simon Petrus, Dadan Ramdan \& Marlan Swandan, Rancangan Kendali Otomotis Kipas Angin

b. Sensor Suhu LM35

Proses baca sensor Suhu LM35

adalah proses membaca suhu dalam suatu ruangan dan yang juga sebagai input dalam rancangan alat ini.

c. Mikrokontroler (NC)

NC yang digunakan adalah jenis AVR yaitu atmega8. Penggunaan pemilihan tersebut karena ukuran yang tepat serta kontroler yang cukup handal untuk rancangan ini. NC diprogram untuk mengendalikan sebuah kipas angin melalui deteksi gerak, yaitu sensor pir. Nc juga mengendalikan atau mengatur waktu berapa lama kipas angin diaktifkan setelah tidak terdeteksi gerak.

d. Driver

Driver adalah rangkaian penguat yang berfungsi menguatkan arus agar sistem dapat mengaktifkan kipas angin. Driver adalah berupa rangkaian transistor yaitu transistor NPN tipe TIP31C, pada saat input transistor akan jenu dan mengalirkan arus sehingga beban pada kolektor dapat dijalankan.

e. Relay

Proses pengaktifan relay adalah proses menjalankan perintah sesuai kondisi hasil pendeteksian. f. Pengharum Ruangan

Proses rancangan alat ini adalah dengan menggabungkan pengharum ruangan pada kipas angin yang dirancang agar dalam suatu ruangan tidak menghasilkan bau tak sedap untuk dihirup manusia dan juga akan tetap menjaga udara dalam ruangan agar tetap sejuk dan wangi.

g. Motor Kipas Angin

Fungsi motor kipas angin adalah komponen yang utama dalam rancangan alat ini yang berfungsi untuk menghasilkan udara yang akan dialirkan bagi tubuh manusia ketika berada dalam ruangan tersebut.

\section{Rancangan Rangkaian Sistem}

Rancangan

rangkaian

menggunakan komponen elektronik dan digital dimana bekerja sesuai dengan fungsinya masing-masing. Sensor Kontroler dan driver bekerja sesuai program yang telah dirancang. 


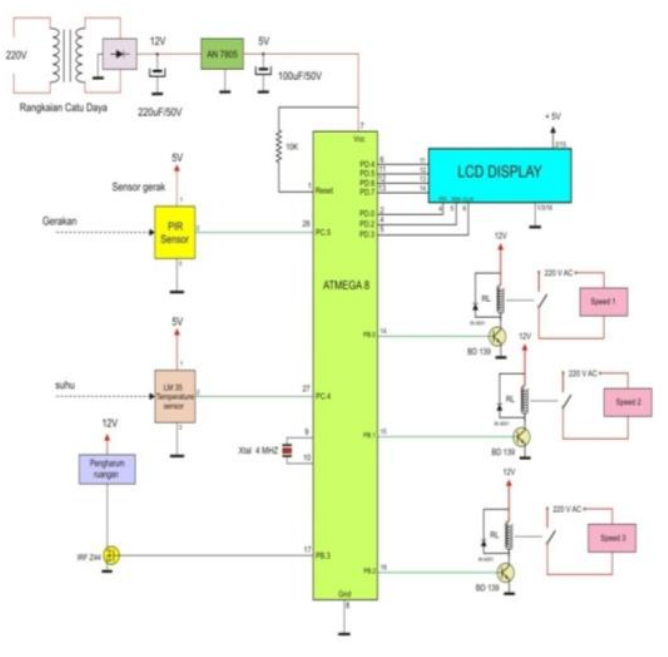

Gambar 3 Rangkaian Sistem

Rangkaian yang digambarkan seperti gambar diatas adalah diagram alir rancangan alat. Aliran dimulai dari inisialisasi dan nilai awal kemudian proses membaca sensor suhu dan gerak melalui input, ketika terdeteksi gerakan manusia dan suhu dalam suatu ruangan mencapai $27^{\circ} \mathrm{C}$, maka secara bersamaan akan mengaktifkan sistem untuk menjalankan Kipas Angin secara otomatis. Metode-metode yang digunakan untuk memperoleh sistem data tersebut adalah sebagai berikut :

a. Menguji Sensor Gerak

Dalam suatu rancangan alat ini perlu melakukan pengamatan atau pengujian untuk mendapatkan pencapaian hasil yang diinginkan dengan cara mengukur output tegangan sensor dengan memberikan input berupa gerak, yaitu gerak hewan kecil, manusia dan mobil yang bergerak.

b. Menguji Sensor Suhu

Menguji sensor suhu adalah dengan menaikkan sensor suhu dan mengukur tegangan keluaran sensor dengan voltmeter. Menaikkan suhu dapat dengan cara mendekatkan sensor dengan sebuah setrikaan atau solder.

c. Mengukur Kecepatan Putar

Untuk mengetahui kecepatan kipas Angin hanyalah dengan mengukur putaran kipas angin dengan menggunakan alat digital yang dapat mampu mengukur rpm pada putaran kipas angin. Dan apabila rotor berputar akan sesuai dengan tingkat kecepatan masing-masing yang ada dalam kipas Angin.

\section{HASIL DAN PEMBAHASAN}

Pengujian dilakukan pada masing-masing komponen sebelum digabungkan dengan rangkaian utama. Berikut ini adalah data hasil pengujian yang dilakukan pada komponen utama yang digunakan.

1. Sensor suhu LM 35

Pengujian dilakukan dengan mengukur tegangan keluaran dari sensor tiap kenaikan suhu yang diberikan. Tujuannya adalah untuk melihat respon 
Simon Petrus, Dadan Ramdan \& Marlan Swandan, Rancangan Kendali Otomotis Kipas Angin

sensor terhadap perubahan suhu. Dengan mengetahui (k) tersebut Sekaligus mencari konstanta kalibrasi kontroler dapat menghitung suhu sensor tersebut. Lokasi pengujian adalah sebenarnya dari tegangan yang masuk ke dalam ruangan ber AC. Kenaikan suhu ADC. dapat dilakukan dengan sebuah lampu 2. Pengujian sensor gerak (PIR) pijar yang didekatkan pada sensor Pengujian dilakukan dengan kemudian suhu sensor diukur dengan mengukur output sensor pada saat tidak sebuah termometer digital. Setiap diberi gerakan dan saat diberi gerakan kenaikan suhu dicatat kenaikan dengan jarak tertentu. tegangannya.

Objek gerak adalah manusia yang Berikut adalah data hasil pengukuran sedang berjalan normal didepan sensor. sensor suhu LM35.

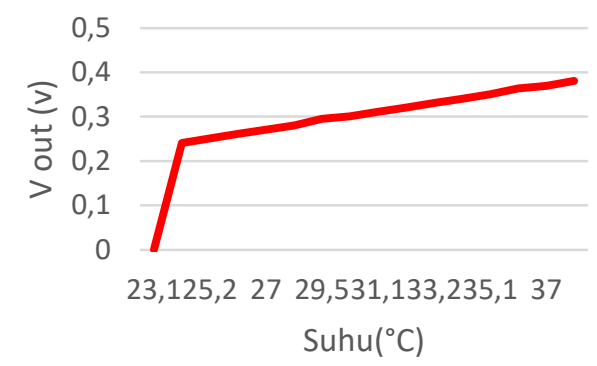

Grafik 1 Pengukuran Sensor Suhu LM35

Analisa:

Dari data diatas dapat dicari konstanta kalibrasi suhu terhadap tegangan yaitu dengan rumus :

$=$ suhu $/ \mathrm{V}_{\text {out }}$ Sensor

Contoh: Suhu $=31{ }^{\circ} \mathrm{C}$ dan Vout $=0,3 \mathrm{~V}$ maka :

$$
\begin{aligned}
& \mathrm{k}=0,3 \mathrm{~V} / 31^{\circ} \mathrm{C} \\
& \mathrm{k}=10 \mathrm{mV} /{ }^{\circ} \mathrm{C}
\end{aligned}
$$

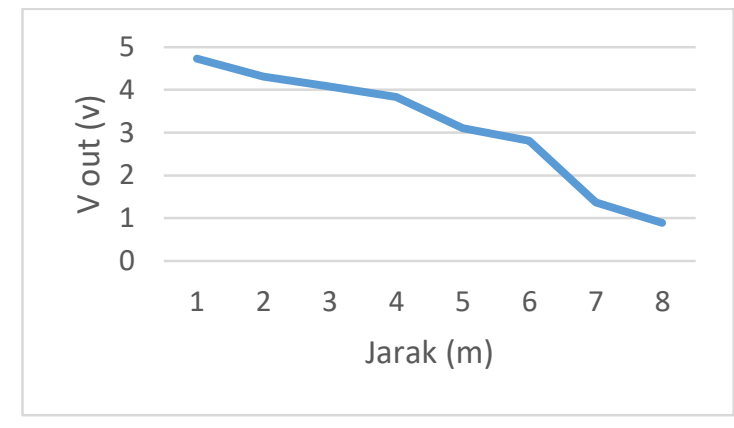

Grafik 2 Pengukuran Tegangan Sensor Gerak

Analisa :

Dari pengujian diatas dapat dilihat bahwa respon sensor pada jarak dekat cukup tinggi dan berkurang seiring bertambahnya jarak pantau. Dengan demikian dapat diambil kesimpulan bahwa jarak efektif mendeteksi gerak oleh sensor adalah dalam radius 5 meter. 
Tabel 2 Tabel Pengukuran Tegangan pin Atmega8

\begin{tabular}{|c|c|}
\hline Pin & Vout(V) \\
\hline 1. & 4,97 \\
\hline 2. & 4,99 \\
\hline 3. & 0,01 \\
\hline 4. & 0,01 \\
\hline 5. & 0,01 \\
\hline 6. & 4,95 \\
\hline 7. & 0,02 \\
\hline 8. & 0,0 \\
\hline 9. & 2,45 \\
\hline 10. & 2,02 \\
\hline 11. & 0,01 \\
\hline 12. & 0,01 \\
\hline 13. & 0,01 \\
\hline 14. & 4,95 \\
\hline 15. & 4,98 \\
\hline 16. & 4,96 \\
\hline 17. & 4,99 \\
\hline 18. & 0,01 \\
\hline 19. & 4,98 \\
\hline 20. & 4,95 \\
\hline 21. & 4,95 \\
\hline 22. & 4,97 \\
\hline 23. & 5,01 \\
\hline 24. & 4,99 \\
\hline 25. & 4,99 \\
\hline 26. & 4,99 \\
\hline 27. & 5,01 \\
\hline 28. & 0,01 \\
\hline
\end{tabular}

Sedangkan data program yang dibuat dalam AVR adalah sebagai berikut :

\begin{tabular}{|c|c|}
\hline DDRB $=0 \times \mathrm{FF}$ & PORTB $=0 \times 2 \mathrm{~F}$ \\
\hline $\mathrm{DDRD}=0 \mathrm{xFF}$ & $\mathrm{PORTD}=0 \times 11$ \\
\hline $\mathrm{DDRC}=0 \mathrm{xFF}$ & PORTC $=0 \times 1 \mathrm{~F}$ \\
\hline
\end{tabular}

Data logik dari keluaran tiap port :

\begin{tabular}{|c|}
\hline PORTB : $\underline{00101111}$ \\
\hline PORTD $: \underline{00010001}$ \\
\hline PORTC $: \underline{00011111}$ \\
\hline
\end{tabular}

Analisa :

Setelah dianalisa dari logik keluaran tiap port dan dibandingkan dengan data program maka dapat dilihat ada kesesuaian antara program dan tidak terdapat perbedaan, sehingga dapat dinyatakan rangkaian kontroler bekerja dengan baik dan terangkai dengan benar.

Tabel 3 Pengujian Motor Kipas Angin

\begin{tabular}{|c|c|c|}
\hline $\begin{array}{c}\text { Temperatu } \\
\text { r Suhu }\end{array}$ & $\begin{array}{c}\text { Kecepata } \\
\mathbf{n}\end{array}$ & $\begin{array}{c}\text { Kecepata } \\
\mathbf{n} \mathbf{~ r p m}\end{array}$ \\
\hline $27^{\circ} \mathrm{C}$ & Kec 1 & $1530 \mathrm{rpm}$ \\
\hline $30^{\circ} \mathrm{C}$ & Kec 2 & $1675 \mathrm{rpm}$ \\
\hline $34^{\circ} \mathrm{C}$ & Kec 3 & $1792 \mathrm{rpm}$ \\
\hline
\end{tabular}

Berikut ini adalah gambar pengukuran kecepatan putaran pada motor Kipas Angin yang dilakukan 
Simon Petrus, Dadan Ramdan \& Marlan Swandan, Rancangan Kendali Otomotis Kipas Angin

dengan memakai Tacho Meter untuk dapat melihat hasil hitungan kecepatan rpm Putaran Kipas Angin :

a) Pengujian Motor Kipas Angin

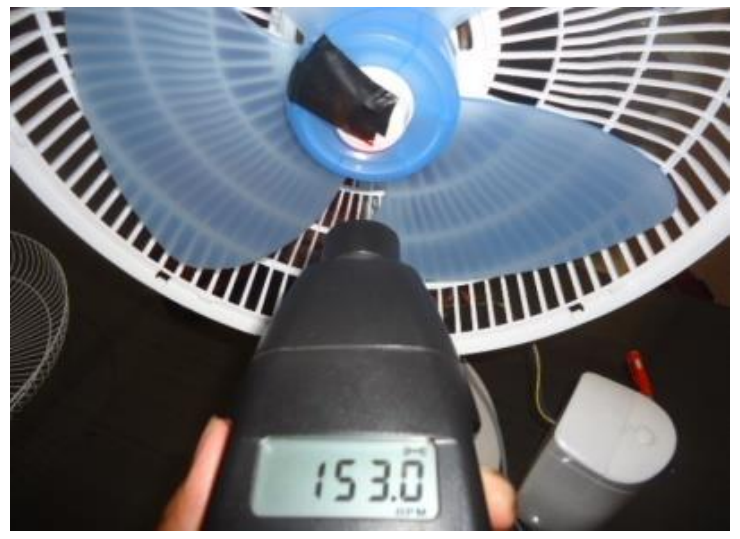

Gambar 4 Pengujian Pada Kecepatan Pertama

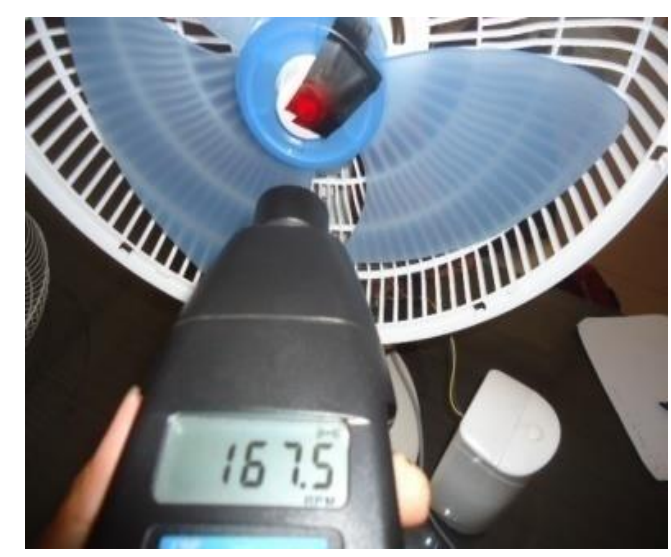

Gambar 5 Pengujian Pada Kecepatan Kedua

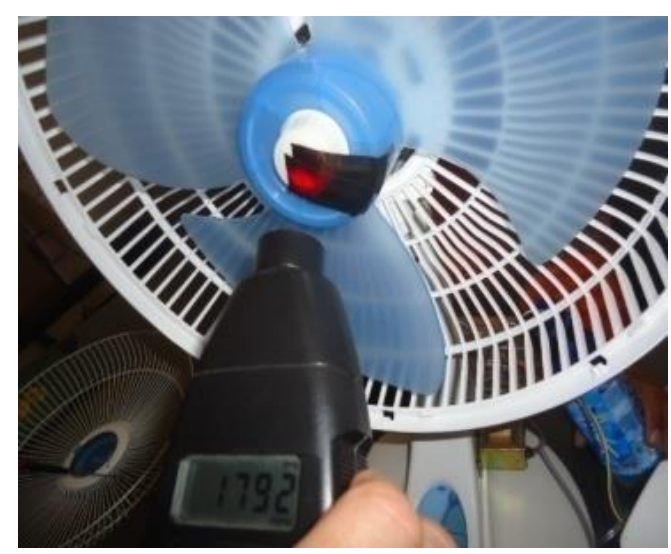

Gambar 6 Pengujian Pada Kecepatan Ketiga b) Pengujian keseluruhan sistem

Pengujian keseluruhan dilakuakan setelah semua komponen tergabung menjadi satu dan diaktifkan. Pengujian dilakukan pada ruang ber AC. Mula-mula aktifkan rangkaian dan diamkan pada kondisi tidak ada orang dengan suhu AC di set pada $25^{\circ} \mathrm{C}$. Pada kondisi ini kipas tidak akan aktif, setelah itu ruangan dimasuki seseorang dengan gerakan pada sensor PIR. Pada keadaan ini kipas angin tetap dalam keadaan off,karena suhu ruang telah dibawah $27^{\circ} \mathrm{C}$. Setelah itu, AC dimatikan beberapa saat (kirakira sekitar 30 menit). Suhu ruang mulai naik, saat kondisi tanpa gerakan dan termometer menunjukkan suhu $28^{\circ} \mathrm{C}$, kipas tetap dalam keadaan Off. Kemudian ruang kembali dimasuki seseorang dengan gerakan pada sensor. Pada saat ini kipas langsung "ON" (Hidup) dan bekerja terus selama beberapa menit. Saat itu gerakan dihentikan dengan orang tersebut keluar dari ruangan. Setelah 5 menit tanpa gerakan kipas angin kembali "Of” (Mati).

Dari pengujian di atas membuktikan bahwa rancangan alat telah bekerja dengan baik sesuai dengan yang diharapkan yaitu mengontrol aktivasi kipas angin sesuai kebutuhan 
dan kondisi ruangan. Dengan demikian dapat dikatakan sistem berhasil dibuat dengan sempurna.

\section{SIMPULAN}

Dari hasil perancangan dan pengujian tentang rancangan Kipas Angin Otomatis yang dikendalikan oleh suhu ruangan dan gerak manusia berbasis mikrokontroler maka penulis dapat mengambil beberapa kesimpulan, yaitu :

Pada suhu ruangan dibawah $27^{\circ} \mathrm{C}$ ketika ruangan ada gerakan manusia dan pada suhu diatas $27^{\circ} \mathrm{C}$ tidak ada gerakan manusia kipas angin tetap Off. Pada suhu diatas $27^{\circ} \mathrm{C}$ ada gerakan manusia kipas angin akan On, dan akan off ketika manusia keluar dari ruangan.

Kipas Angin Otomatis yang menggunakan mikrokontroler Atmega8 sebagai pengendali berdasarkan suhu ruangan dan gerak manusia mampu bekerja dengan baik sebagai alat yang mengoptimalkan penghematan listrik.

\section{DAFTAR PUSTAKA}

Abisabrina.Fungsi.Transistor. https://.wordpress.com/2010/08/2014 fungsi-dasar-transistor, Buku Penerbit ANDI Jl. Beo 38-40 Yogyakarta Telp.(0274) 588282 email:penerbit@andipublisher.comwebsi te: www.andipublisher.com

Debora. Pengertian Dioda. http://rangkaianelektronika.info/penger tian-dan-fungsi-dioda/
Diva.Tentang PIR. http://elektronikadasar.info/sensorgera k.htm http:// ghojer.blogspot.co.id/2013/09/ macam-macam-jenis-motor-listrik.html

Teori sensor suhu lm35.http://repository.usu. ac.id/bitstream/123456789/25239/3/ Chapter\%20II.pdf

Wildan.Tentang Relay. http://teknikelektronika.com/pengertia n-relay-fungsi-relay/

Winoto, Ardi,2011, Mikrokontroler AVR Atmega8 Dan Pemograman Dengan Bahasa C pada Win AVR, Jakarta, Informatika 